\title{
Initial Infection and Colonization of Leaves and Stems of Cling Peach by Tranzschelia discolor
}

\author{
A. Soto-Estrada, H. Förster, D. A. DeMason, and J. E. Adaskaveg
}

First, second, and fourth authors: Department of Plant Pathology; and third author; Department of Botany and Plant Sciences, University of California, Riverside 92521.

Accepted for publication 13 April 2005.

\begin{abstract}
Soto-Estrada, A., Förster, H., DeMason, D. A., and Adaskaveg, J. E. 2005. Initial infection and colonization of leaves and stems of cling peach by Tranzschelia discolor. Phytopathology 95:942-950.

Initial infection processes and the subsequent colonization of leaves and young stems of peach by Tranzschelia discolor were studied. On leaves where multiple disease cycles of peach rust occur during the growing season, urediniospores germinated after $4 \mathrm{~h}$ of wetness. Germ tubes became septate and formed appressoria only over leaf stomata beginning $18 \mathrm{~h}$ after inoculation. No appressoria, however, formed over stomata of positive replicas of leaf surfaces indicating nonthigmotropic responses of germ tubes. On young, primary-growth stems (ca. 8 weeks old), stomata were mostly closed, less frequent than on leaves, and recessed from the surface of the cuticle of the epidermis. Although appressoria formation was not observed on inoculated stems, germ tube growth of uredinio-

apparently a less common event that was reflected by a lower occurrence of stem lesions compared with that of leaf lesions in our potted plant inoculation studies and previous field observations. Still, stem lesions are important as sources of primary inoculum each spring and were reproduced in this study for the first time. Fungal colonization of leaves and stems was subepidermal-intercellular and haustoria were commonly found within mesophyll or cortical cells, respectively. No fungal colonization was observed in cambial stem tissue. Vascular tissue was also not colonized and delimited lesions in leaves and stems. Morphological host responses were not observed in infections on either leaves or young stems. In older stems ( $>32$ weeks old), however, the infection was delimited by a wound periderm after uredinial formation. Furthermore, with continued secondary growth, stems recovered and fungal lesions became part of the bark tissue of woody branches. Thus, the fungus must infect primary-growth branches each year to establish stem lesions.
\end{abstract} spores was directional toward stomata. Penetration of stem tissue is
Stone fruit rust is caused by the fungus Tranzschelia discolor (Fuckel) Tranzschel \& Litvinov (18). Ecologically, rust fungi are biotrophs or parasites found only on living host tissue in nature (16). T. discolor is a macrocyclic rust producing five different stages (basidial, spermogonial, aecial, uredinial, and telial) (7). Additionally, the fungus is heteroecious, alternating between two different host species, Prunus spp. and species in the family Ranunculaceae $(4,7)$. In mild climates, the fungus can survive on Prunus spp. as dikaryotic mycelium and in the uredinial stage without infecting the alternate host (18). Because the uredinial stage of the fungus is capable of repeated infections on Prunus spp., this host can be seriously damaged, causing economic losses. Severe rust epidemics have occurred sporadically in California (18). On peach, in addition to leaves and fruit, the fungus can infect primary-growth stem tissue. The infection of stems is thought to be latent and allows the fungus to survive during dormancy of the deciduous tree (11).

Disease symptoms on leaves initially become evident as pale yellowish green spots on both leaf surfaces. Lesions become bright yellow and angular in shape as the disease develops and are apparently limited by the larger veins $(11,23)$. With age, leaf lesions turn necrotic and have yellow halos. Lesions on the lower leaf surface become rusty brown with the production of powdery masses of urediniospores produced in uredinia. On stems, infections begin as water-soaked lesions. The epidermis becomes raised and ruptures with the development of uredinia and emergence of urediniospores. Stem lesions develop in the spring as

Corresponding author: J. E. Adaskaveg; E-mail address: jim.adaskaveg@ucr.edu

DOI: 10.1094/PHYTO-95-0942

(c) 2005 The American Phytopathological Society longitudinal splits on the stem (11), but no permanent damage occurs and branches recover from infections with age.

Goldsworthy and Smith (11) in 1931 provided the only histological study that is available on peach rust. They describe uredinia in leaves, stems, and fruit, and cross sections demonstrate their subepidermal development and the presence of numerous haustoria in mesophyll cells. In more recent studies, Allen et al. (3) investigated appressorial formation of 27 rust fungi in response to topographical signals and concluded that $T$. discolor was nonthigmotropic but they did not indicate how this fungus penetrates peach leaves. Although most rust fungi penetrate their host through the stomatal openings, exceptions to this mechanism are known (15).

One objective of the current study was the evaluation of early infection processes including penetration and development of the fungus in leaf tissue as it relates to foliar symptoms using highresolution light and electron microscopy. Furthermore, time studies were conducted on the development of infection structures of the fungal pathogen. Because stem infections are important as sources of primary inoculum in the spring and are critical for survival of the fungus in milder climates such as California, comparative observations were also conducted on stems. Thus, the wound-healing and recovery processes of stems from stem lesions that preclude the pathogen from permanently damaging the stem tissue were also studied histologically.

\section{MATERIALS AND METHODS}

Source and production of inoculum and culture maintenance. In 1996, urediniospores of T. discolor (designated R-96) were collected from leaves of cling peach (cv. Ross) in a commercial orchard in Marysville, CA. Potted peach plants (cv. Lovell) 
were grown from seed (Fowler Nurseries, Inc., Newcastle, CA) and maintained year-round in a greenhouse at 15 to $30^{\circ} \mathrm{C}$. To maintain the biotrophic pathogen, every 1 to 2 months three peach plants were inoculated using a hand sprayer with a spore suspension of the fungus $\left(1 \times 10^{5}\right.$ urediniospores per ml $)$ made in sterile distilled water (SDW) containing $0.01 \%$ Tween 20 . Clear plastic bags were placed over the plants for $24 \mathrm{~h}$ and the plants were incubated in the greenhouse. For reinoculation of plants, urediniospores were collected in a conical test tube $(13 \mathrm{~cm}$ long, $2.5 \mathrm{~cm}$ in diameter) trap (24; J. E. Adaskaveg, personal communication) with a vacuum pump. The conical test tube had a cork with two glass tubes inserted through it. One of the glass tubes had a spiral end that extended $9 \mathrm{~cm}$ into the tube, while the other glass tube was straight and extended $3 \mathrm{~cm}$ into the tube when the cork was inserted. The collecting hose (B-44-3, Tygon, Inc., Cleveland, $\mathrm{OH})$ was attached to the spiral glass tube and the vacuum hose to the straight glass tube. Collected spores were suspended in SDW with Tween $20(0.01 \%)$ and new plants were inoculated as described previously.

For inoculum production for the subsequent studies on the infection process of $T$. discolor, spores from infected peach leaves (cv. Lovell) were first washed off with SDW using a hand sprayer. After 4 days, the newly formed urediniospores were collected and prepared as inoculum as described previously. Inoculations were always done on the same day the urediniospores were collected. Spore germination was determined for every inoculation by placing four evenly spaced $20-\mu$ drops of the spore suspension in a $9 \mathrm{~cm}$ petri plate containing water agar (BactoAgar, Difco Laboratories, Detroit, MI). After a 24-h incubation period in the dark at $20^{\circ} \mathrm{C}, 100$ urediniospores were evaluated for each drop of inoculum on the plate. A urediniospore was considered germinated when the germ tube was at least twice as long as the width of the spore.

Urediniospore germination and appressorial formation on peach leaves and stems. For microscopic observations on the infection process, leaves from potted cv. Lovell peach plants were cut into pieces $(5 \times 5 \mathrm{~mm})$. The pieces were placed upper surface down in petri dishes containing wet filter paper (Whatman No. 2 filter paper, England) and were inoculated by placing a $10-\mu \mathrm{l}$ droplet of spore suspension $\left(1 \times 10^{4}\right.$ urediniospores per $\left.\mathrm{ml}\right)$ on the lower surface. Petri dishes containing the samples were incubated in the dark at $20^{\circ} \mathrm{C}$. For bright-field microscopy, three leaf pieces each were sampled $4,8,12,18,24,48$, and $72 \mathrm{~h}$ after inoculation and cleared in a saturated chloral hydrate solution $(5 \mathrm{~g} / 2 \mathrm{ml}$ of water) for 24 to $48 \mathrm{~h}$. Tissues were stained with $0.1 \%$ acid fuchsin solution $(0.1 \mathrm{~g}$ of acid fuchsin in $100 \mathrm{ml}$ of $85 \%$ lactic acid) for 30 to $60 \mathrm{~s}$, rinsed with tap water, and observed under a compound microscope (Axioskop, Carl Zeiss, Germany). The experiment was repeated twice.

Additionally, negative and positive leaf replicas were prepared from 'Lovell' peach leaves. For negative replicas, we used hydrophilic vinyl polysiloxane impression material (Exaflex, GC America Inc., Chicago, IL) that contains base and catalyst products. These two products were mixed, spread uniformly over ca. $1 \mathrm{~cm}^{2}$ of the lower leaf surface, and let dry. The impressions were removed and positive replicas were made by applying a thin layer of collodium (Acros Organics, Fair Lawn, NJ). Once dried, the collodium replicas were peeled off, inoculated with a spore suspension as described previously, and observed after $24 \mathrm{~h}$ under a compound microscope. This experiment was done twice with five replications per experiment.

For scanning electron microscopy (SEM), inoculated leaf material was fixed in osmium tetroxide vapor for $2 \mathrm{~h}$ (19), dehydrated in a graded series of ethanol concentrations $(50,75,95$, and $100 \%$ ) for $5 \mathrm{~min}$ each, and chemically dried in 50,75 , and $100 \%$ hexamethyldisilizane for $5 \mathrm{~min}$ for each concentration. Three leaf samples for each wetness period were mounted on SEM stubs and sputter-coated with a gold-palladium target. Specimens were ob- served with a Philips XL30-FEG SEM (FEI Philips, Hillsboro, OR) set at an acceleration voltage of $15 \mathrm{kV}$. The experiment was done twice.

Stems ( 3 to $5 \mathrm{~mm}$ in diameter, 10 to $30 \mathrm{~cm}$ long) of potted peach plants were spray-inoculated until runoff with an aqueous spore suspension $\left(1 \times 10^{5}\right.$ urediniospores per $\left.\mathrm{ml}\right)$ of $T$. discolor with a hand sprayer. Plants were then covered with clear plastic bags for $24,36,48$, or $72 \mathrm{~h}$ to obtain selected wetness periods and placed into growth chambers at $20^{\circ} \mathrm{C}$ with a 12 -h photoperiod of fluorescent (1,570 lux) and incandescent light (1,715 lux). One plant was used for each wetness period, and one stem was sampled per plant. The experiment was repeated four to five times for each wetness period. Stems were cut into 5- to 7-mm long segments, split in half longitudinally, cleared, stained, and observed under the compound microscope as described previously. For SEM observations, stems were treated similar to leaf samples as described previously.

Effect of selected wetness periods on incidence and severity of leaf and stem lesions. For leaf infections, six plants were spray-inoculated $\left(1 \times 10^{5}\right.$ urediniospores per $\left.\mathrm{ml}\right)$ as described previously and bagged for each of two wetness periods ( 24 or $36 \mathrm{~h}$ ). For stem infections, three stems of each of 7 to 10 plants were spray-inoculated and bagged for each of two wetness periods (24 or $48 \mathrm{~h}$ ). Plants were incubated in the greenhouse at 15 to $30^{\circ} \mathrm{C}$ and were evaluated for incidence (percentage of leaves infected or percentage of plants with stems infected) and severity (number of lesions per leaf or number of stem lesions per plant) 12 days (leaves) or 6 weeks (stems) after inoculation. This experiment was done twice. For each experiment, wetness period, and tissue type, mean values and standard deviations of disease incidence were calculated. For disease severity, mean values and standard deviations for each experiment were determined.

Comparison of leaf and stem stomata. Stomata of leaf and stem tissues were compared using bright-field microscopy. For this, peach leaves were cut into pieces of $25 \mathrm{~mm}^{2}$, mounted in a drop of water on glass slides, and observed. Three-week-old stems of potted plants were cut into $1-\mathrm{cm}$ sections and each section was split in half longitudinally. The cortex of each split section was removed and transferred to a glass slide for observation. Samplings of stems were done in the morning, mid-day, and late afternoon. For both leaves and stems, stomata were observed within 30 min of sampling. The size and number of stomata per unit area were determined and morphological comparisons of stomata were made on five samples of each tissue, each depicting $1 \mathrm{~mm}^{2}$. An analysis of variance was performed on length, width, and number of stomata for each tissue type and least significant difference mean separation procedures were performed on the data using the Statistical Analysis System (SAS, version 8.2; SAS Institute, Cary, NC).

Fungal colonization of peach leaves and stems. Peach leaves (cv. Lovell) with rust symptoms were collected 10, 12, and 15 days after inoculation and incubation in a growth chamber at $20^{\circ} \mathrm{C}$. Symptomless leaves from noninoculated plants were used as controls. Five pieces $(5 \times 5 \mathrm{~mm})$ from lesions or healthy tissue from different leaves from each of three experiments were fixed in $2 \%$ glutaraldehyde in $0.05 \mathrm{M}$ sodium phosphate buffer at $\mathrm{pH}$ 7.2 for $24 \mathrm{~h}$, rinsed in water, and dehydrated in a graded series of ethanol concentrations $(25,50,75,95$, and 100\%) for 15 to $20 \mathrm{~min}$ for each solution. After dehydration, tissue samples were infiltrated in $2: 1,1: 1,1: 2$, and $0: 1(\mathrm{vol} / \mathrm{vol})$ ethanol/catalyzed methacrylate solutions (JB-4-acrylic monomer $n$-butanoxyethanol, Polysciences, Inc., Warrington, PA). Samples were infiltrated in each mixture for at least $2 \mathrm{~h}$ and in $100 \%$ methacrylate for $24 \mathrm{~h}$. Samples were transferred to a plastic mold containing a mixture of $0.2 \mathrm{ml}$ of accelerator solution ( $N, N$-dimethylaniline) and $10 \mathrm{ml}$ of catalyzed methacrylate, and molds were covered with Parafilm and polymerized at $25^{\circ} \mathrm{C}$. Embedded tissue was sectioned into $3-\mu \mathrm{m}$ sections with a rotary microtome (American 
Optical, Buffalo, NY) equipped with a glass knife. Sections were mounted on microscope slides, stained with methylene blue-azure II-basic fuchsin (14), and observed with a bright-field microscope. For SEM, leaf tissue was fixed in Carnoy Lebrun fixative
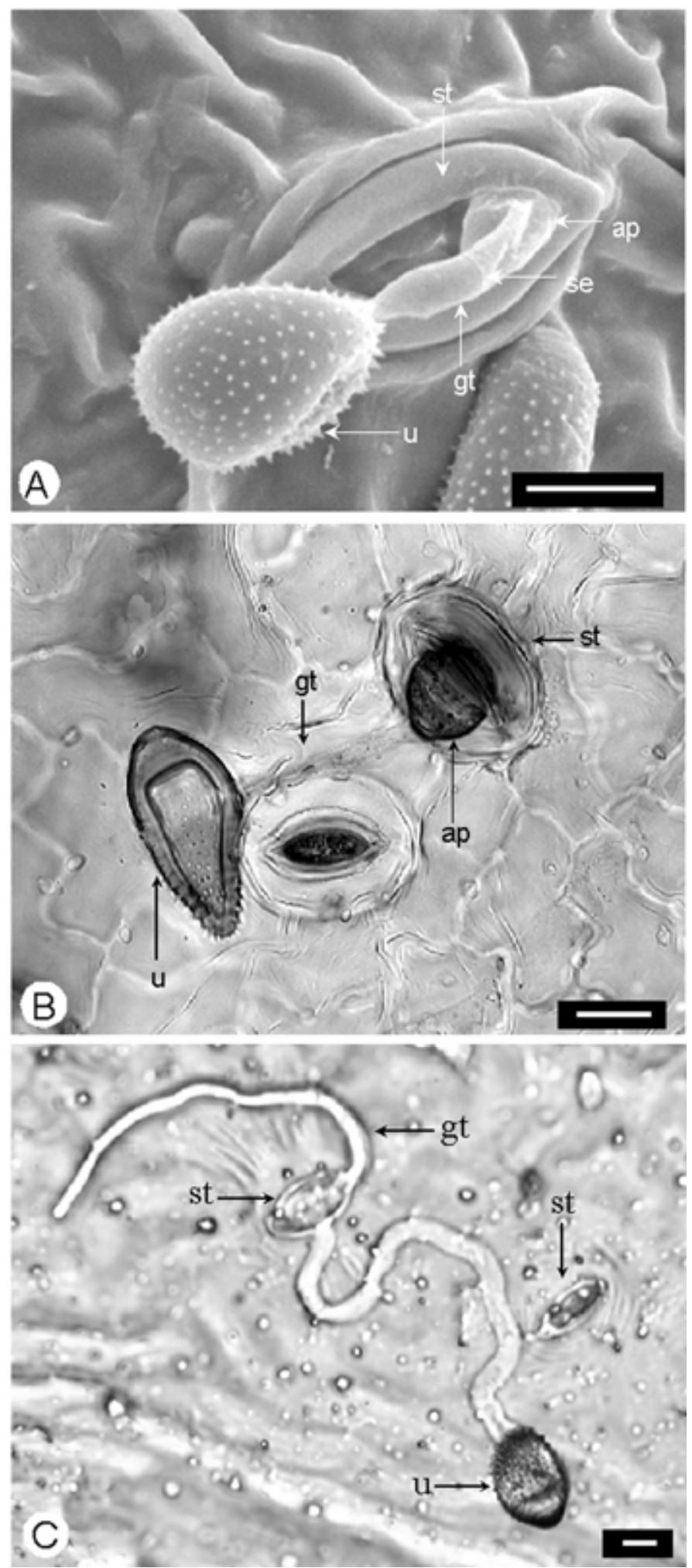

Fig. 1. Germinating urediniospores of Tranzschelia discolor on peach leaves and on a collodium leaf replica. A, Scanning electron micrograph showing a urediniospore, germ tube, septum, and appressorium over an open stoma $24 \mathrm{~h}$ after inoculation. B, Light micrograph of a urediniospore $72 \mathrm{~h}$ after inoculation. C, Light micrograph of a urediniospore and germ tube with no appressorium $24 \mathrm{~h}$ after inoculation on a collodium leaf replica. Abbreviations: ap = appressorium, gt = germ tube, $\mathrm{se}=$ septum, $\mathrm{st}=$ stoma, and $\mathrm{u}=$ urediniospore . Bars $=10 \mu \mathrm{m}$.
(5), dehydrated as described previously, and dried with carbon dioxide in a critical point drier (Type CPD 010, Balzers Union, Liechtenstein). Samples were prepared and observed as described in the previous section.

For evaluating fungal colonization of stems, 20 diseased $\mathrm{cv}$. Andross peach stems were collected in the field in early (April), mid- (May), and late spring (June) of 1997 and 1998. Additionally, healthy stems and stems with swollen, water-soaked lesions were sampled 4 to 5 weeks after inoculation of plants in the greenhouse. For this, five stems with or without (healthy) lesions were cut into $5-\mathrm{mm}$ sections, and each section was split in half longitudinally. Samples $(5 \times 3 \times 2 \mathrm{~mm})$ were fixed, dehydrated, and infiltrated in methacrylate as described previously, except the first three infiltration steps were for $24 \mathrm{~h}$ and two final infiltration steps in $100 \%$ methacrylate were for 4 to 6 weeks each. For SEM, stems were processed and prepared for observation as described previously, except $2 \%$ glutaraldehyde was used as fixative. At the time of the June field sampling, 20 stem lesions were tagged each year and reevaluated for rust lesions when the stems were approximately 22 to 28 months old.

\section{RESULTS}

Urediniospore germination and appressorium formation on peach leaves and stems. Based on bright-field microscopy and SEM observations of inoculated peach leaves, urediniospores of T. discolor mostly germinated with a single germ tube after a 4-h wetness period. Germ tubes originated from germ pores of the urediniospore and grew on the leaf surface for up to $18 \mathrm{~h}$ before subsequent differentiation. Germ tube length ranged from 30 to over $100 \mu \mathrm{m}$. Germ tubes became septate and appressoria were formed only over leaf stomata beginning $18 \mathrm{~h}$ after inoculation regardless of germ tube length (Fig. 1A and B). At $24 \mathrm{~h}$ after inoculation, ca. $90 \%$ of the urediniospores had germinated and $35 \%$ of the germinated urediniospores had formed appressoria. Brightfield microscopy of acid fuchsin-stained tissue showed that germ tubes of urediniospores were turgid and filled with cytoplasm 4 to $24 \mathrm{~h}$ after inoculation. Beginning at $48 \mathrm{~h}$ and commonly at $72 \mathrm{~h}$, however, cytoplasm was no longer observed in germ tubes, and consequently, germ tubes were collapsed (Fig. 1A and B). A septum was commonly present immediately before the appressorium (Fig. 1A). On collodium leaf replicas, urediniospores had germinated and developed long germ tubes $24 \mathrm{~h}$ after inoculation. No appressoria were formed even when germ tubes came into close contact with stomata (Fig. 1C).

On stem tissue, germ tubes of urediniospores grew toward or over the mostly closed stomata, but appressoria were not observed for any of the wetness periods (Fig. 2A and B). Furthermore, germ tubes commonly grew in a circular pattern around stomata (Fig. 2B). As on leaf tissue, germ tube length varied considerably but was generally about $200 \mu \mathrm{m}$ after a 24 -h wetness period.

Effect of selected wetness periods on incidence and severity of leaf and stem lesions. Lesions first developed as water-soaked areas on leaves 8 to 10 days after inoculation. For both wetness periods and experiments, all leaves were infected. Severity of leaf infections ranged from $17.4 \pm 2.8$ to $35.8 \pm 13.3$ (mean \pm standard deviation) and $83.7 \pm 49.6$ to $230.3 \pm 74.5$ for the $24-$ and $36-h$ wetness periods, respectively. Stem lesions also developed as watersoaked lesions on young (primary-growth) stems 4 to 5 weeks after inoculation of peach plants in the greenhouse, however, at a much lower incidence and severity compared with leaf infections. Incidence of infected plants with uredinial stem lesions was $42.9 \% \pm$ $0 \%$ and $35 \% \pm 7.1 \%$ for the $24-$ and 48 -h wetness periods, respectively. The severity for the two experiments was $4.7 \pm 2.5$ and $15.7 \pm 20.2$ lesions per plant for the 24 -h wetness period and $2.3 \pm$ 1.2 and $5.5 \pm 7.7$ lesions per plant for the 48 -h wetness period.

Comparison of leaf and stem stomata. The size and number of stomata per unit area were significantly different $(P<0.05)$ 
between leaf and stem tissues. The average number of stomata on the lower leaf surface was $250 / \mathrm{mm}^{2}$, whereas on stem tissue it was $23 / \mathrm{mm}^{2}$. The average size of stomata was $30 \times 20 \mu \mathrm{m}$ for leaves and $40 \times 30 \mu \mathrm{m}$ for stems. On leaves, stomata were clearly visible and slightly raised above the leaf surface. On stems, the stomata were slightly recessed (Fig. 2A and B) and sometimes partially covered by epicuticular wax. Leaf stomata generally were opened. Stem stomata were mostly closed in microscopic observations of fixed tissues, although samples were taken at different times of the day (Fig. 1A and B, Fig. 2A and B).

Fungal colonization of peach leaves and stems. Sections of noninoculated leaf tissue showed a typical leaf anatomy of a seed plant (10) with a single-layered epidermis on upper and lower sides, stomata in the lower epidermis, and palisade parenchyma and spongy mesophyll tissues (Fig. 3). The vascular bundles were delimited from the mesophyll by the bundle sheaths. On inoculated leaves, disease symptoms generally developed after 8 to 10 days of incubation. Histological sections of tissue samples taken after this incubation time indicated that the palisade parenchyma and the spongy mesophyll were colonized by intercellular mycelium of the fungus. Mycelium was often observed in cells surrounding smaller vascular bundles. Vascular bundles (i.e., veins) containing xylem and phloem cells, however, were not colonized regardless of size (Fig. 4A). Sheath cells, however, were colo-
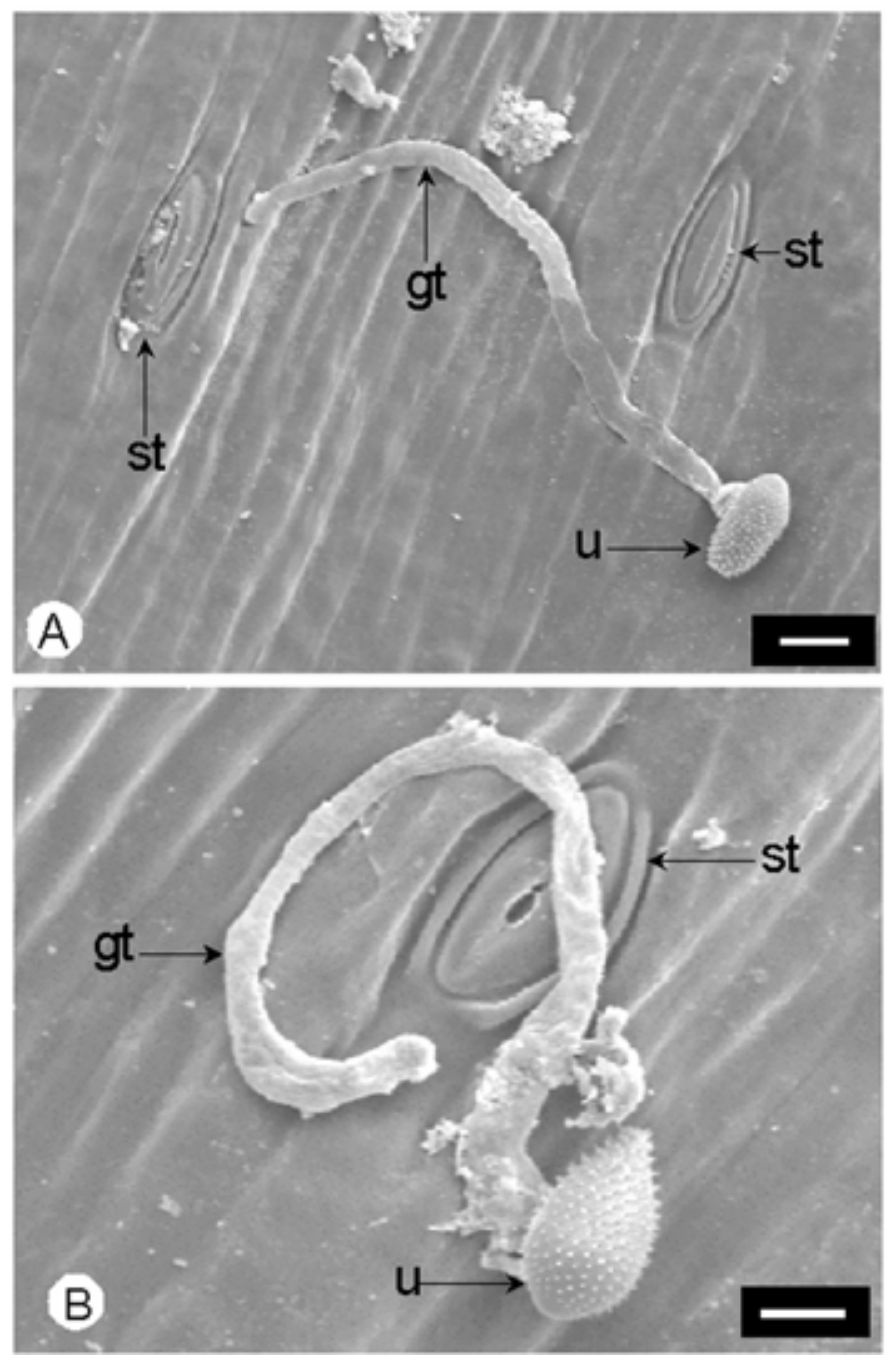

Fig. 2. Scanning electron micrographs of germinating urediniospores of Tranzschelia discolor on stem tissue. A, Germ tube growing between two closed stomata without appressorium formation. B, Germ tube growing over and around a stoma without an appressorium. Abbreviations: gt = germ tube, $\mathrm{st}=$ stoma, and $\mathrm{u}=$ urediniospore. Bars $=10 \mu \mathrm{m}$. nized. Haustoria were commonly found in sheath cells and especially in the spongy mesophyll (Fig. 4B). Twelve days after inoculation, the spongy mesophyll was more extensively colonized than the palisade tissue and uredinial initials were observed developing from fungal pseudoparenchyma tissue in the spongy mesophyll of the leaf. Fifteen days after inoculation, mature uredinia enlarged with the production of urediniospores and ruptured through the epidermal tissue (Fig. 5). Hyaline capitate paraphyses were observed among the urediniospores of the uredinia. SEM of lower leaf surfaces showed slightly to extensively raised and ruptured epidermal tissue 10 days (Fig. 6A) to 12 days (Fig. 6B) after inoculation. Uredinia were fully developed ca. 15 days after inoculation and numerous urediniospores were exposed (Fig. 6C).

Stems of noninoculated greenhouse plants or healthy peach stems from field collections showed a typical peach stem anatomy that consisted of a one-layered epidermis with a cuticle, a cortex of parenchyma tissue with prominent intercellular spaces, vascular cambium between the phloem and xylem, and a pith of parenchyma tissue (Fig. 7A). Observations on second-year healthy stems collected in the field in May and June indicated that with the initiation of the vascular cambium a periderm had formed in late June (Fig. 7B).

Uredinial initials on greenhouse-inoculated and field-collected stems formed subepidermally from a dense mass of pseudoparenchyma mycelium and raised the stem epidermis, but did not rupture it as shown by SEM (Fig. 8A). As uredinia increased in size with the production of the urediniospores, the epidermis began to bulge, cracked open, and finally ruptured exposing urediniospores as shown in SEM (Fig. 8B and C) and in light micrographs of transverse sections (Fig. 9A and B). Among the uredinia observed, most developed beneath stem stomata (Fig. 8B). Light microscopy of transverse sections of infected stems on inoculated greenhouse plants indicated that mycelium of the fungus first grew subepidermally and intercellularly, and was localized in the

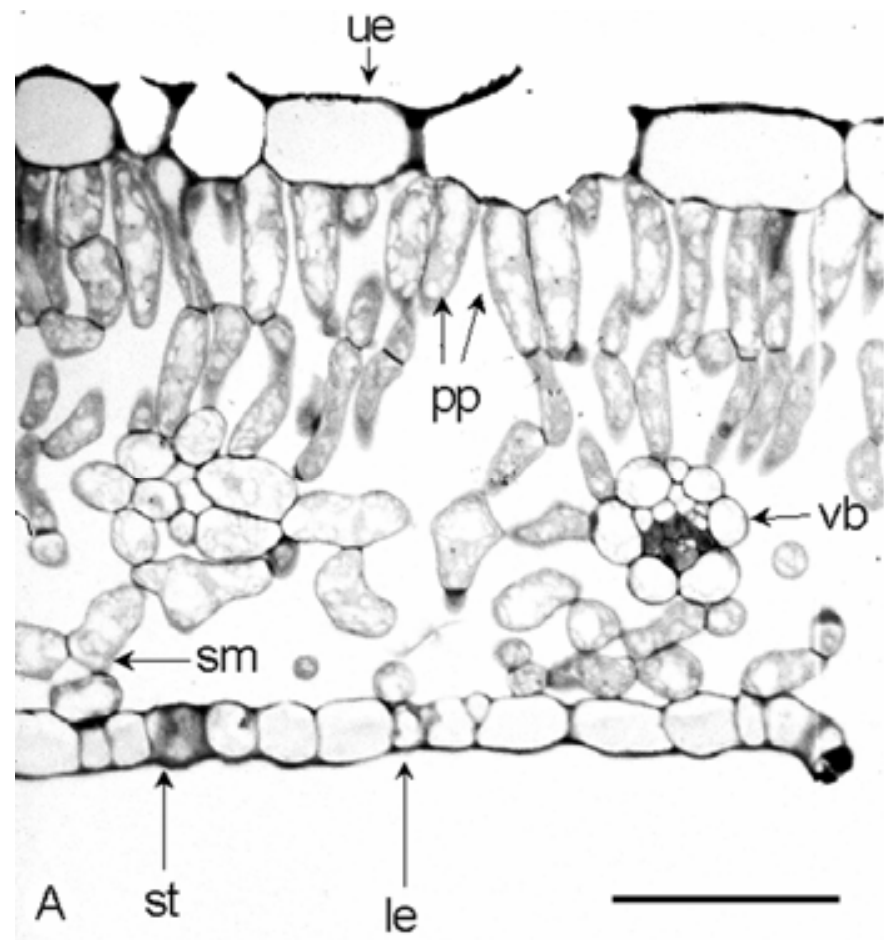

Fig. 3. Light micrograph of cross section of a healthy cling peach leaf showing the upper and lower epidermis, a small vascular bundle, and palisade parenchyma and spongy mesophyll cells. Abbreviations: le = lower epidermis, $\mathrm{pp}=$ palisade parenchyma, $\mathrm{sm}=$ spongy mesophyll, $\mathrm{st}=$ stoma, $\mathrm{ue}=$ upper epidermis, and $\mathrm{vb}=$ vascular bundle. $\mathrm{Bar}=50 \mu \mathrm{m}$. 
cortex tissue (Fig. 9A) where haustoria were commonly observed (Fig. 4C). Fungal mycelium did not develop into the vascular cambium. Cortical cells were often reduced in size or collapsed (Fig. 9A) compared with healthy tissue (Fig. 7A). Uredinia were morphologically similar in greenhouse and field studies on leaves and stems.

In field-infected stems collected in the spring (May), a wound periderm had formed around and under the localized infection (Fig. 9C). In cross section, the wound periderm was concave in shape and extended from both sides of the healthy epidermis. No fungal mycelium was observed beyond the wound periderm. In late-June samples, tissue contained by the wound periderm had become shriveled and collapsed with no evidence of additional fungal sporulation or growth (Fig. 9D). Tagged stems that had uredinial lesions 28 months before, recovered with continued secondary growth. At this time, lesions became part of the bark tissue of woody branches and were barely visible due to the fact that peripheral tissues were sloughed off.

\section{DISCUSSION}

The early infection processes of the stone fruit rust fungus T. discolor on cling peach leaves and stems are described for the first time in this study using histological and SEM techniques. In addition, investigations on subsequent host colonization explain characteristics of the host-pathogen interaction, such as symptom expression on leaves and stems and host recovery from stem infections.

Germination of urediniospores and germ tube development were similar to previous reports on $T$. discolor $(8,9,11)$ and other rust fungi $(25,26)$. Urediniospores mostly germinated with a single germ tube after a 4-h wetness period on both leaves and stems. Appressorium formation that began $18 \mathrm{~h}$ after inoculation was only observed on leaf tissue where it occurred only over stomata. Allen et al. (3), in urediniospore germination studies on microfabricated topographies with selected heights of ridges, concluded that $T$. discolor belongs to a group of rust fungi where appressorium formation is not triggered by thigmotropic stimuli. This was confirmed by our experiments with collodium leaf replicas where germ tubes produced no appressoria even when they came into close contact with stomata. This indicates that some other mechanism is triggering appressorium formation in $T$. discolor. In Puccinia graminis f. sp. tritici, for example, carbon dioxide concentration was considered a critical factor in the penetration of wheat (26). Other factors such as unidentified volatile and nonvolatile cuticular or cell wall materials have also been implicated in the stimulation of appressorium formation of rust fungi $(12,13,17)$. The potential role of factors like these for appressor-

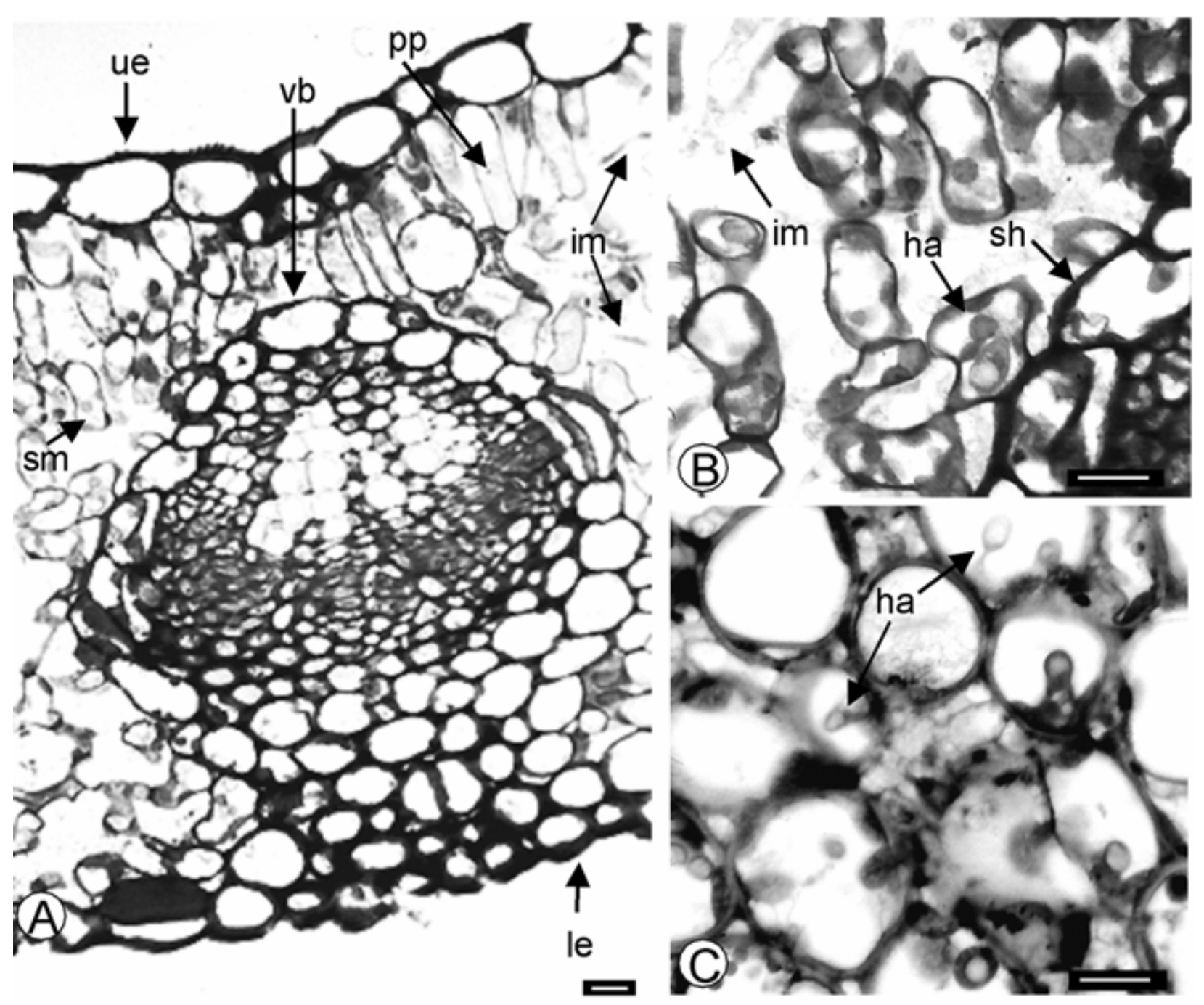

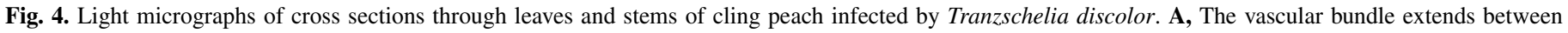

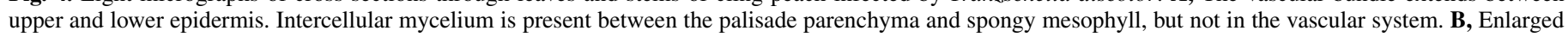

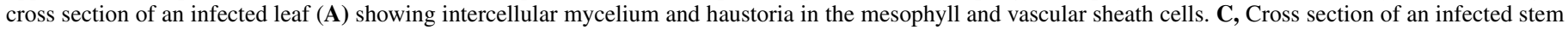

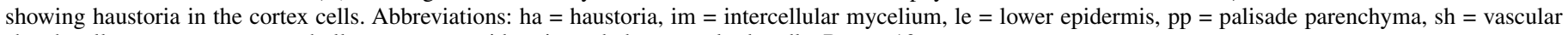
sheath cell, $\mathrm{sm}=$ spongy mesophyll, ue $=$ upper epidermis, and vb = vascular bundle. Bars $=10 \mu \mathrm{m}$. 
ium formation of T. discolor is also supported by the fact that appressoria were not observed on stem tissues where stomata were mostly closed, although a large number of samples was investigated. Instead, germ tubes continued to elongate and often grew in close proximity to stem stomata or in a circular pattern around stomata, regardless of sampling time during the day. Apparently, volatile chemical stimuli from substomatal plant tissues did not diffuse out in sufficient amounts to trigger germ tube differentiation into appressoria. Thus, the reduced number of stomata on stems compared with leaves and the fact that the stomata were mostly closed could explain why stem penetration was not observed, few stem lesions developed in greenhouse experiments, and during epidemics in the field, stem lesions were also much less common than leaf lesions (22).

Stem infections were reproduced for the first time during this study in greenhouse experiments. In comparisons of tissues, incidence of leaf lesions was always $100 \%$, whereas only ca. 30 to

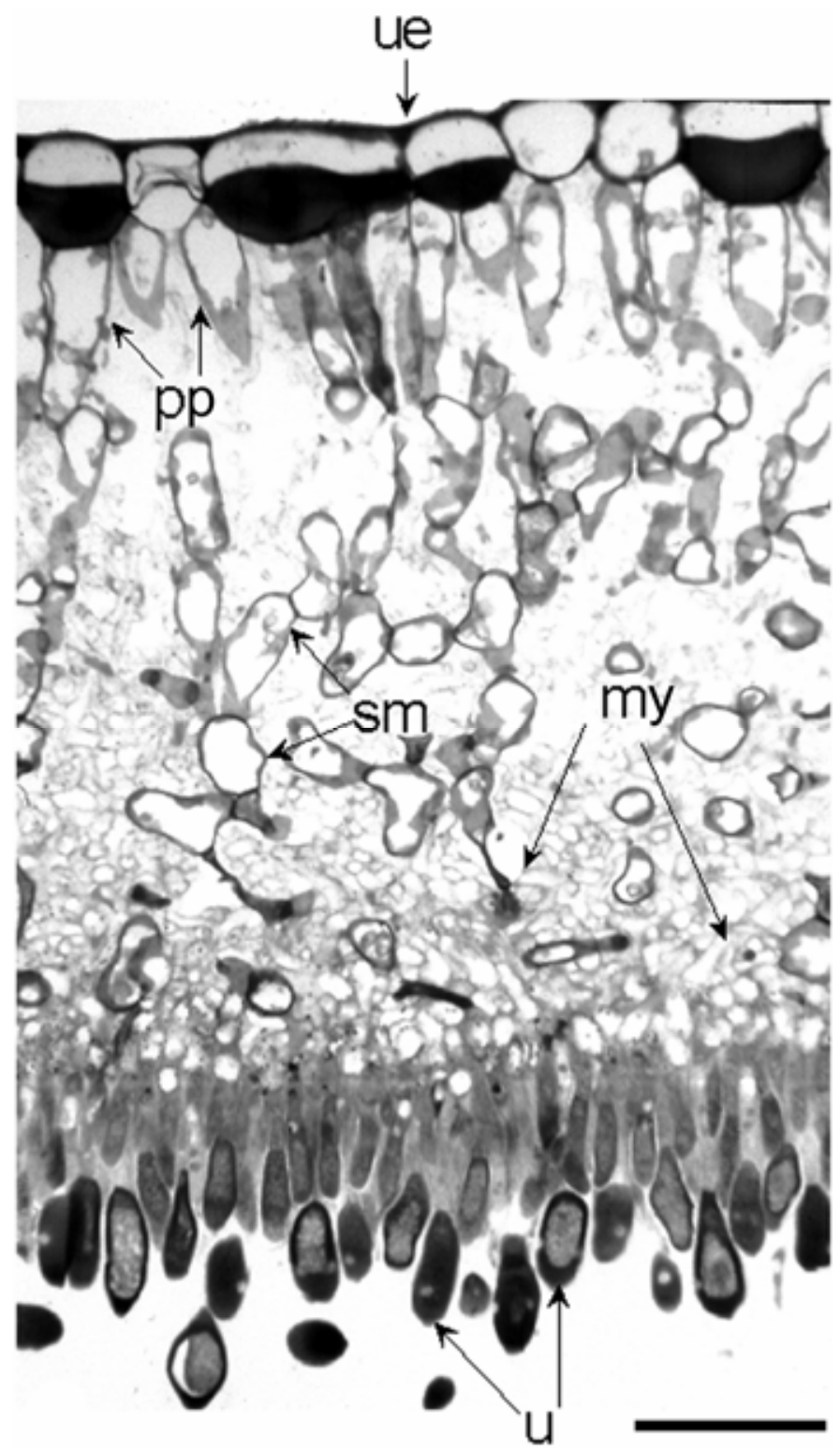

Fig. 5. Light micrograph of cross section of a cling peach leaf showing an advanced stage of leaf colonization and a portion of a uredinium of Tranzschelia discolor. The mycelium colonized the palisade parenchyma and spongy mesophyll. The lower epidermis is ruptured and the urediniospores are exposed. Abbreviations: le $=$ lower epidermis, $\mathrm{my}=$ mycelium, $\mathrm{pp}=$ palisade parenchyma, $\mathrm{sm}=$ spongy mesophyll cells, $\mathrm{u}=$ urediniospore, and ue $=$ upper epidermis. Bar $=50 \mu \mathrm{m}$.
$43 \%$ of the inoculated plants developed stem lesions. These results on stem tissue are similar to previous field studies where no more than $50 \%$ of stem samples had rust infections and the severity ranged from two to nine lesions per 30-cm length of stem (22).
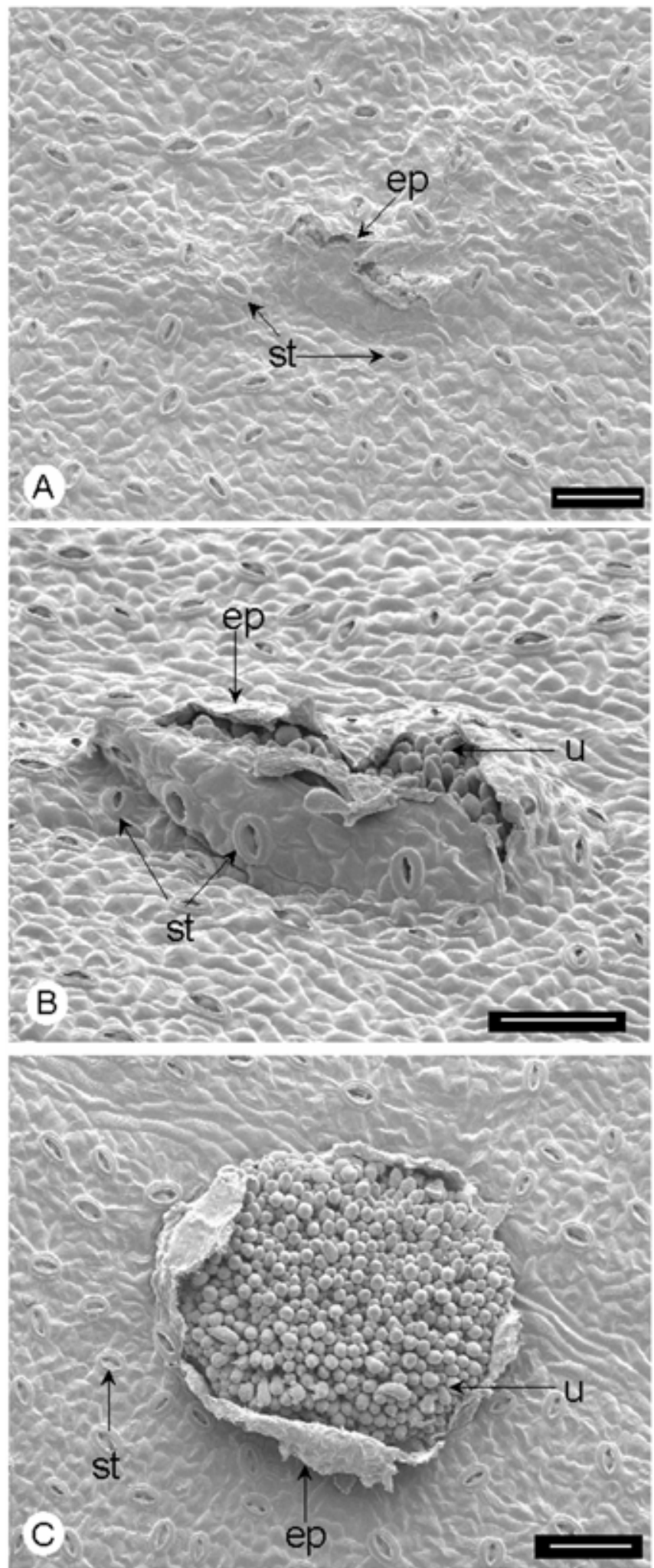

Fig. 6. Scanning electron micrographs showing different stages of uredinial development of Tranzschelia discolor on inoculated lower leaf surfaces of cling peach. A, Leaf epidermal tissue is raised and partially ruptured by developing uredium 10 days after inoculation. B, Ruptured leaf epidermis exposing uredium and urediniospores 12 days after inoculation. C, Mature uredinium bearing urediniospores 15 days after inoculation. Abbreviations: ep = epidermis, $\mathrm{st}=$ stoma, and $\mathrm{u}=$ urediniospores. Bars $=100 \mu \mathrm{m}$. 
Severity of leaf and stem lesions was variable between our two experiments. Leaf lesions were more severe after longer wetness periods ( $24 \mathrm{~h}$ versus $36 \mathrm{~h}$ ), whereas stem lesions had a higher incidence and were more severe in the 24 -h than in the 48 -h wetness period treatments in each of the experiments. As discussed above, differences in the susceptibility of these tissues were probably due to differences in the number and state (opened versus closed) of stomata. Interestingly, symptoms on leaves developed in 8 to 10 days, whereas on stems, uredinia developed after a much longer symptomless incubation period of 4 to 5 weeks. This long incubation period for development of uredinia on stems was supported by field observations by Goldsworthy and Smith (11) and Roth (20). These authors noted that symptomless stems in the fall developed uredinia in the spring and they concluded that latent stem infections are an overwintering mechanism of the fungus.

Previously, Goldsworthy and Smith (11) observed that peach rust lesions on leaves were apparently delimited by larger leaf veins. We provide the first histological evidence that $T$. discolor does not colonize the vascular tissue within bundles, except for

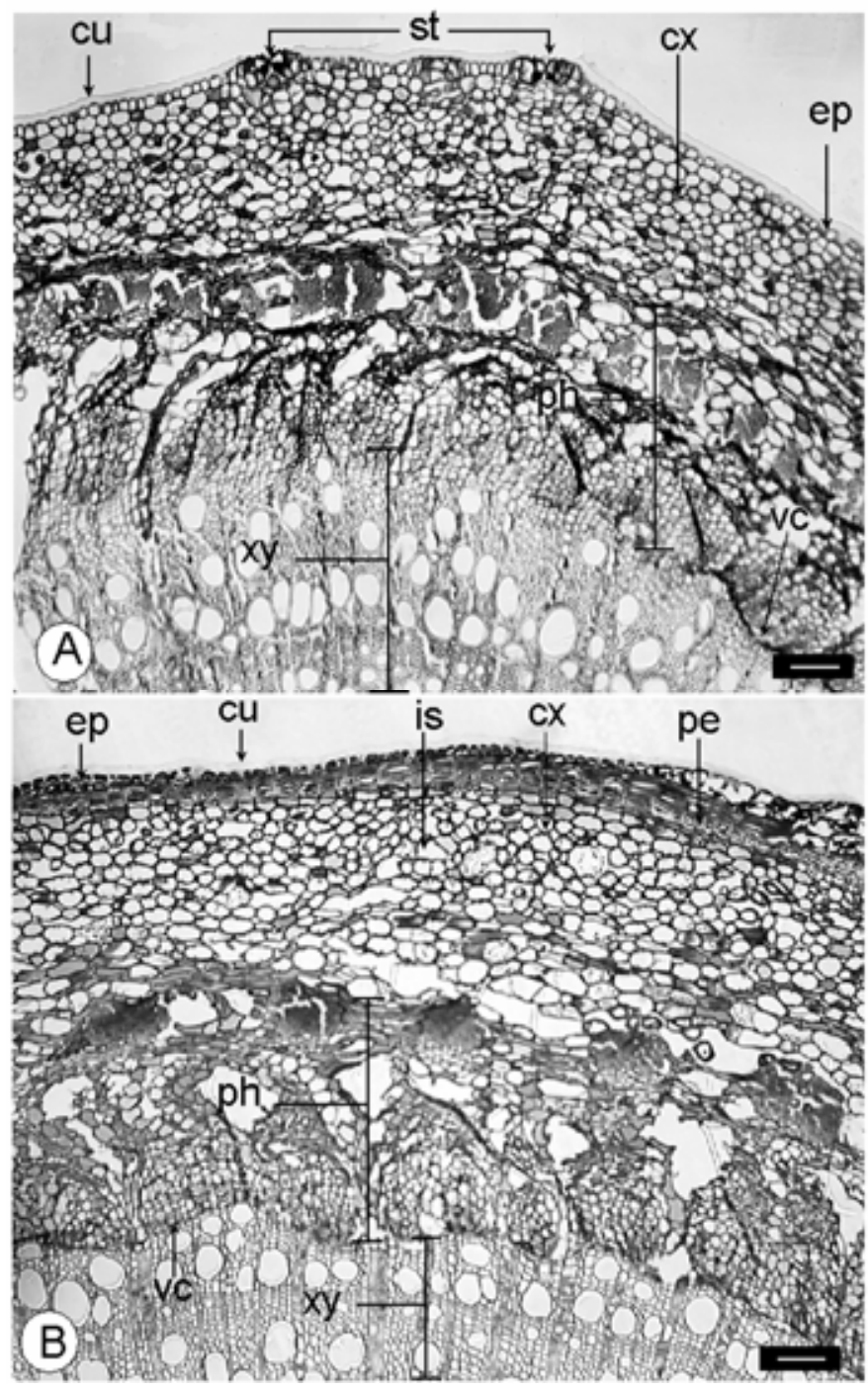

Fig. 7. Light micrographs of cross sections of healthy stems of cling peach. A, Nine-month-old stem collected in April showing epidermis with cuticle, cortex, phloem, vascular cambium, and xylem. Arrows indicate stomata (st). B, One-year-old stem collected in June showing development of the periderm during secondary growth. The epidermis is being sloughed off in the upper right. Abbreviations: $\mathrm{ep}=$ epidermis, $\mathrm{cu}=$ cuticle, $\mathrm{cx}=$ cortex, is = intercellular space, pe $=$ periderm, $\mathrm{ph}=$ phloem, $\mathrm{vc}=$ vascular cambium, and $\mathrm{xy}=$ xylem. Bars $=50 \mu \mathrm{m}$. the sheath cells, regardless of the size of the vascular bundles. This may be due to the fact that a portion of the vascular bundles contains nonliving xylem cells and living cells within the bundle lack intercellular spaces where mycelium of the biotrophic fungus

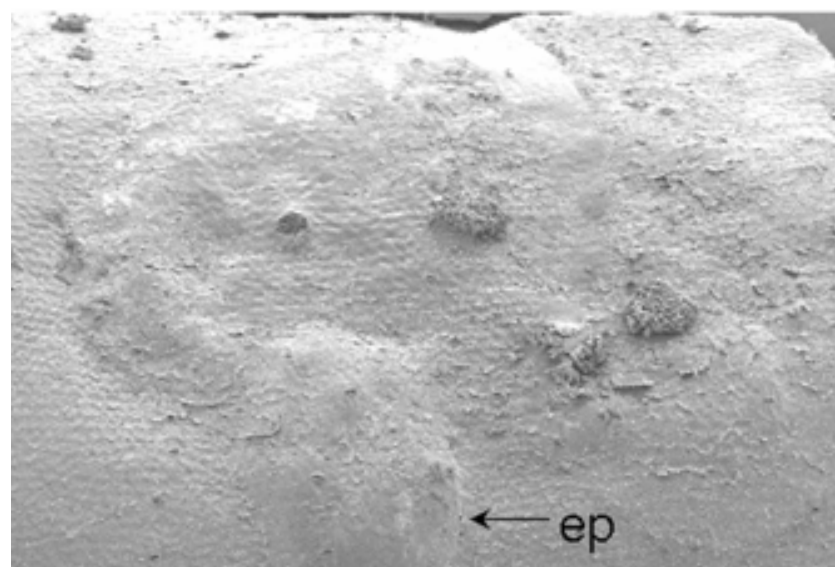

A
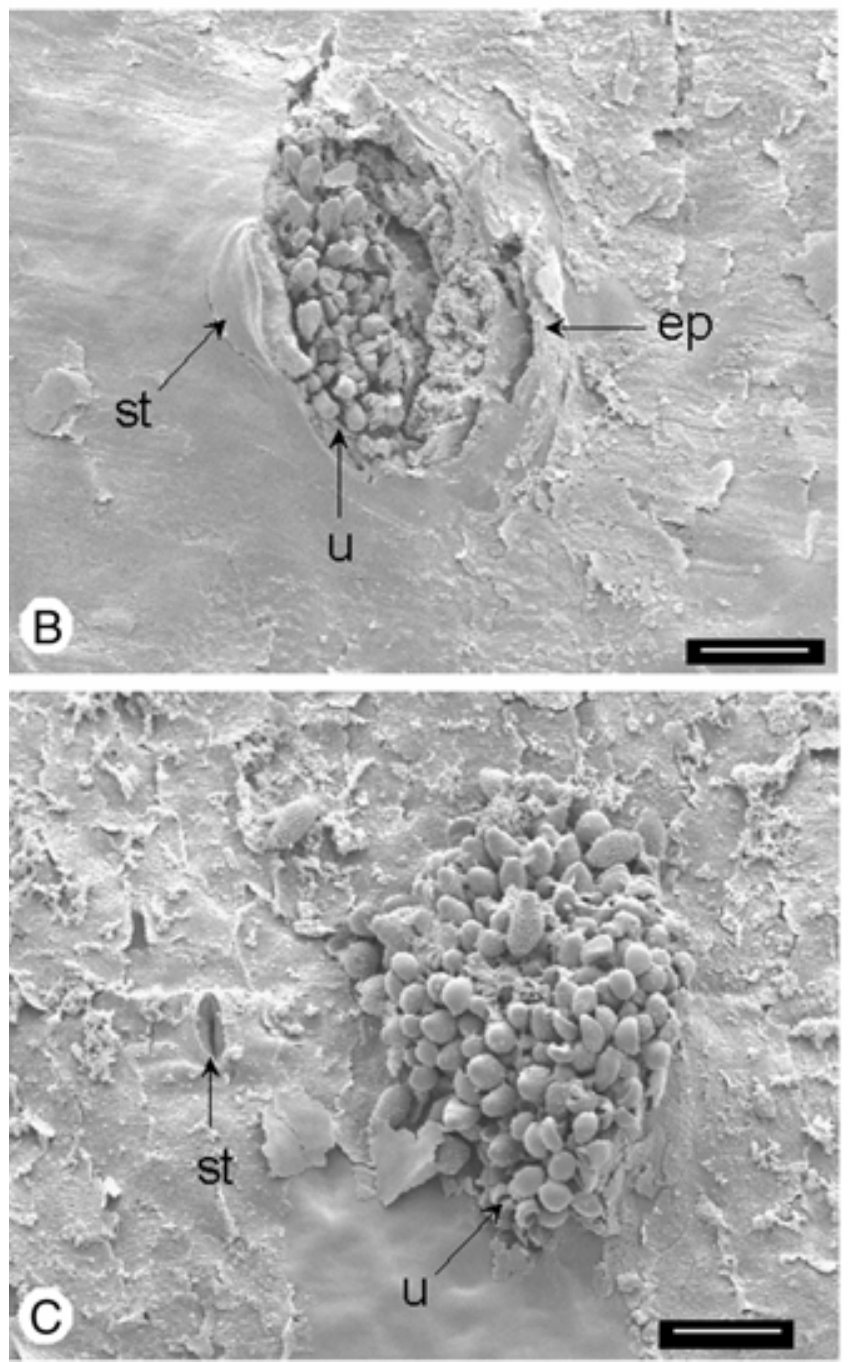

Fig. 8. Scanning electron micrographs showing different stages of uredinial development of Tranzschelia discolor on inoculated stems of cling peach. A, Early uredinial development on stems that were inoculated in the greenhouse showing swollen epidermal tissue. B, Emerging urediniospores rupturing the stem epidermis from beneath a stoma. C, Mature uredinium bearing urediniospores on stem surface. Abbreviations: $\mathrm{ep}=$ epidermis, $\mathrm{st}=$ stoma, and $\mathrm{u}=$ urediniospores. Bars $=100 \mu \mathrm{m}$. 
could grow. Thus, leaf lesions are angular in shape because they are delimited by the larger vascular bundles that extend between upper and lower epidermal tissue.

Histological evaluations of stem tissue showed that fungal colonization was intercellular, subepidermal, and localized to the cortex similar to descriptions by Goldsworthy and Smith (11). Inward fungal colonization was at first limited by the primary phloem (vascular tissue) and later by a wound periderm. The dense arrangement of cells in the primary phloem lacked intercellular spaces similar to vascular bundles in leaf tissue and therefore possibly prevented the invasion of the fungus. Thus, fungal colonization of stems was again limited by vascular tissue as in leaves.

In older stems, a wound periderm that was concave in shape and extended from both sides of the healthy epidermis limited the extent of stem infections. This periderm functioned as a barrier to lateral and vertical colonization of the stem cortex because no hyphae were found in or beyond this tissue. The biotrophic rust fungus apparently does not invade the meristematic cells that form the phellogen or the nonliving phellem cells that develop at maturity of the wound periderm. A wound periderm never formed in response to leaf infections as described for some other foliar pathogens or mechanical injuries of Prunus spp. $(1,2,21)$. Presumably, the biotrophic rust fungus prevented this host response in leaf tissue even after uredinial formation within the leaf lesion.

The wound periderm around stem infections developed in older (>32 weeks old) primary-growth stems by mid-spring (e.g., May) after uredinia were formed in early spring (e.g., April). The time it takes to form a wound periderm in peach as a reaction to wounds or pathogen invasion has been studied (6). Mechanical wounding or inoculation with Cytospora leucostoma resulted in differentiation of a periderm or some of its components (phellogen and phellem) in 10 to 21 days. Similarly, in our study, approximately 30 to 45 days passed between stem samplings and wound periderm development.

Because $T$. discolor did not colonize or injure the vascular cambium of the peach stem, stems fully recovered with continued secondary growth. Thus, lesions that developed on ca. 10-month-old stems were still present in the following spring (ca. 22-month-old stems), but did not produce new uredinia. By the end of the third growing season (ca. 28-month-old stems), however, lesions became part of the bark tissue and were no longer evident. Goldsworthy and Smith (11) observed sporulation on 1- and 2-year-
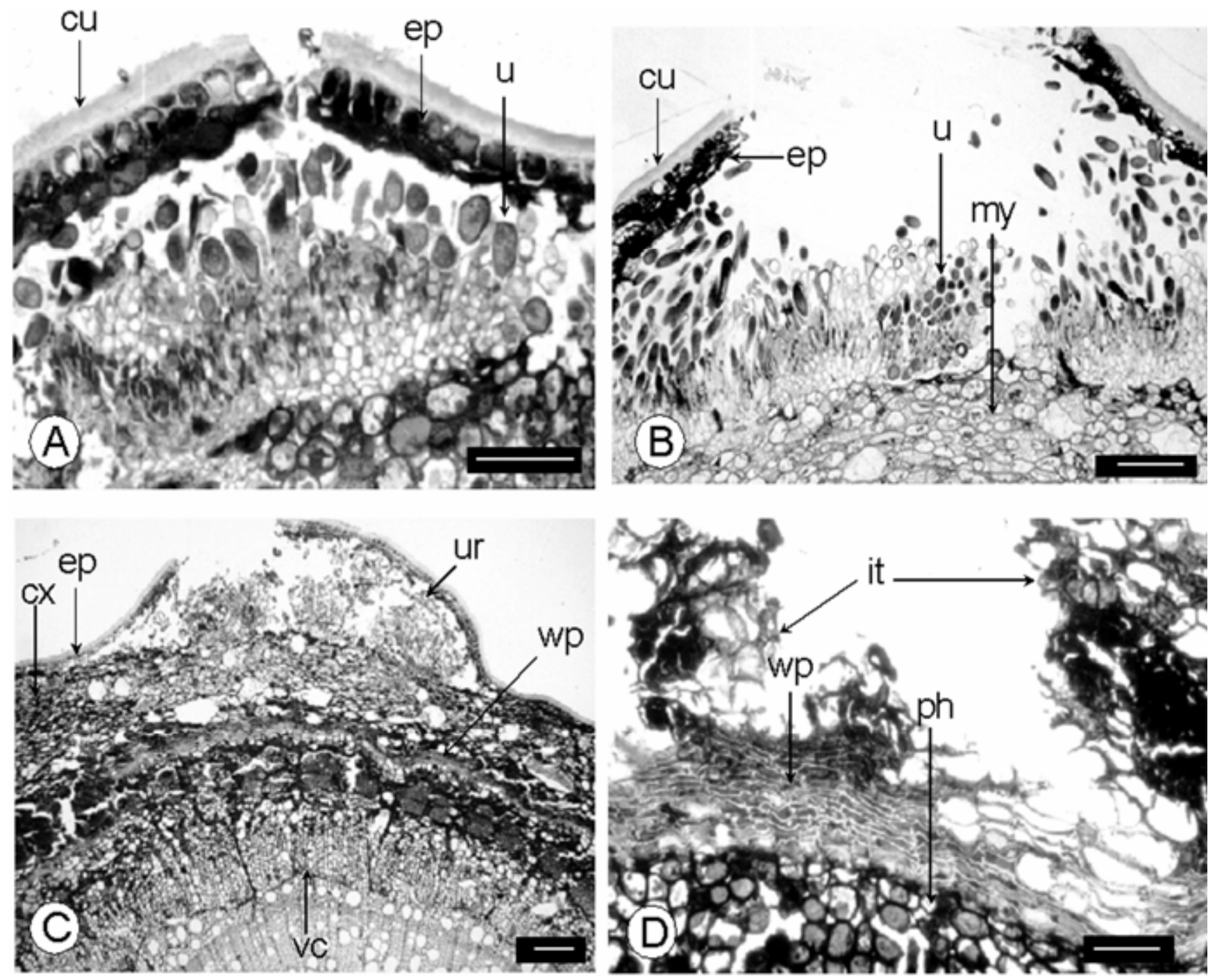

Fig. 9. Light micrographs of cross sections of cling peach stems before and after wound periderm formation with different stages of uredinial development of Tranzschelia discolor. A, Subepidermal development of a uredinium and urediniospores in stem tissue. Note that the thick cuticle and epidermis are mostly undisrupted. B, Advanced stage of uredinial development showing ruptured epidermis. C, Development of a wound periderm below the uredinium and between the cortex and phloem tissue in field-collected stems in the spring (May). D, Compartmentalization of diseased tissue above a wound periderm in field-collected stems in late spring (June). Note healthy phloem cells below the wound periderm. Abbreviations: $\mathrm{cx}=\mathrm{cortex}, \mathrm{cu}=\mathrm{cuticle}, \mathrm{ep}=\mathrm{epidermis}$, it $=$ infected tissue, $\mathrm{my}=$ mycelium, $\mathrm{ph}=$ phloem, $\mathrm{u}=$ urediniospore, $\mathrm{ur}=$ uredinium, $\mathrm{vc}=$ vascular cambium, and $\mathrm{wp}=$ wound periderm. Bars $=30 \mu \mathrm{m}$. 
old stems, whereas Roth (20) indicated that sporulation occurred on 1-year-old stems. In our field observations and in other field surveys (22), we confirmed the observations of Roth (20). Although no host variety was mentioned in the previous publications $(11,20)$, differences in cling peach cultivars grown previously in California or South Africa and currently in California may explain these differences in observations.

\section{ACKNOWLEDGMENTS}

We thank the California Cling Peach Board and the J. M. Ogawa Endowment for financially supporting this research, B. Manji for insightful discussions, D. Thompson for technical assistance in field experiments, and D. Eddleman for sharing his experiences with histological fixatives and techniques.

\section{LITERATURE CITED}

1. Adaskaveg, J. E. 1992. Defense mechanisms in leaves and fruit of trees to fungal infection. Pages 205-245 in: Defense Mechanisms of Woody Plants Against Fungi. R. A. Blanchette and A. R. Biggs, eds. SpringerVerlag, New York.

2. Adaskaveg, J. E. 1995. Conidial morphology, host colonization, and development of shot hole of almond caused by Wilsonomyces carpophilus. Can. J. Bot. 73:432-444.

3. Allen, E. A., Hazen, B. E., Hoch, H. C., Kwon, Y., Leinhos, G. M. E., Staples, R. C., Stumpf, M. A., and Terhune, B. T. 1991. Appressorium formation in response to topographical signals by 27 rust species. Phytopathology 81:323-331.

4. Arthur, J. C. 1934. Manual of the Rusts in United States and Canada. Purdue Research Foundation, Lafayette, IN.

5. Barbosa, P. 1974. Manual of Basic Techniques in Insect Histology. Autumn Publishers, Amherst, MA.

6. Biggs, A. R. 1984. Boundary-zone formation in peach bark in response to wounds and Cytospora leucostoma infection. Can. J. Bot. 62:2814-2821.

7. Cummins, G. B., and Hiratsuka, Y. 1983. Illustrated Genera of Rust Fungi. The American Phytopathological Society, St. Paul, MN.

8. Ellison, P. J., Cullis, B. R., Bambach, R. W., and Kable, P. F. 1990. The effect of temperature on in vitro germination and germ tube growth of urediniospores of Tranzschelia discolor. Aust. J. Agric. Res. 43:451-464.

9. Ellison, P. J., Cullis, B. R., and Kable, P. F. 1990. The effect of light and temperature on in vitro germination and germ tube growth of urediniospores of Tranzschelia discolor. Aust. J. Agric. Res. 43:451-464.
10. Esau, K. 1977. Anatomy of Seed Plants. John Wiley \& Sons, New York.

11. Goldsworthy, M. C., and Smith, R. E. 1931. Studies on rust of cling peaches in California. Phytopathology 21:133-168.

12. Grambow, H. J., and Grambow, G. E. 1978. The involvement of epicuticular and cell wall phenols of the host plant in the in vitro development of Puccinia graminis f. sp. tritici. Z. Pflanzenphysiol. 90:1-9.

13. Grambow, H. J., and Riedel, S. 1977. The effect of morphogenically active factors from host and nonhost plants on the in vitro differentiation of infection structures of Puccinia graminis f. sp. tritici. Physiol. Plant Pathol. 11:213-224.

14. Humphrey, C. D., and Pittman, F. E. 1974. A simple methylene blue-azure II-basic fuchsin stain for epoxy-embedded tissue sections. Stain Technol. 49:9-14.

15. Hunt, P. 1968. Cuticular penetration by germinating uredospores. Trans. Br. Mycol. Soc. 51:103-112.

16. Littlefield, L. J. 1981. Biology of the Plant Rusts: An Introduction. Iowa State University Press, Ames, IA.

17. Maheshwari, R., Allen, P. J., and Hildebrandt, A. C. 1967. Physical and chemical factors controlling the development of infection structures from urediospore germ tubes of rust fungi. Phytopathology 57:855-862.

18. Ogawa, J. M., and English, H. 1991. Diseases of Temperate Zone Tree Fruit and Nut Crops. University of California, Div. Agric. Nat. Res. Publ. 3345.

19. Postek, M. T., Howard, K. S., Johnson, A. H., and McMichael, K. L. 1980. Scanning Electron Microscopy. A Student's Handbook. Ladd Research Industries, Williston, VT.

20. Roth, G. 1966. Tranzschelia discolor (Fuck.) Tranz. et Litv. on peaches in Transvaal Lowveld, South Africa. Phytopathol. Z. 56:141-150.

21. Samuel, G. 1927. On the shot-hole disease caused by Clasterosporium carpophila and on the "shot-hole" effect. Ann. Bot. 41:375-404.

22. Soto-Estrada, A., and Adaskaveg, J. E. 2004. Temporal and quantitative analyses of stem lesion development and foliar disease progression of peach rust in California. Phytopathology 94:52-60.

23. Soto-Estrada, A., Eddleman, C. D., and Adaskaveg, J. E. 2000. Development and symptom expression of rust caused by Tranzschelia discolor in shoots and leaves of cling peach. (Abstr.) Phytopathology 90(suppl.): S121.

24. Teng, P. S., and Close, R. C. 1977. Mass efficiency of two urediniospore collectors. N. Z. J. Exp. Agric. 5:197-199.

25. Wynn, W. K. 1976. Appressorium formation over stomates by the bean rust fungus: Response to a surface contact stimulus. Phytopathology 66:136-146.

26. Yirgou, D., and Caldwell, R. M. 1968. Stomatal penetration of wheat seedlings by stem and leaf rusts in relation to effects of carbon dioxide, light, and stomatal aperture. Phytopathology 58:500-507. 